RODRIGUES, M.C. et al. Efeito de diferentes concentrações espermáticas para diluição do semen de varrões sobre a viabilidade do sêmen refrigerado. PUBVET, Londrina, V. 5, N. 19, Ed. 166, Art. 1123, 2011.

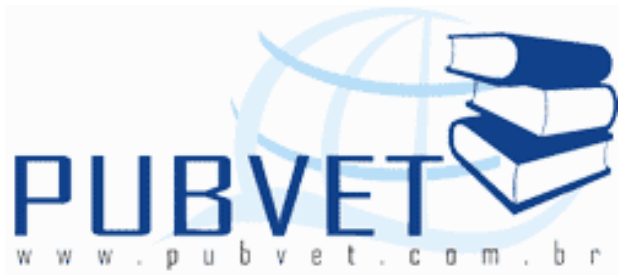

PUBVET, Publicações em Medicina Veterinária e Zootecnia.

\title{
Efeito de diferentes concentrações espermáticas para diluição do semen de varrões sobre a viabilidade do sêmen refrigerado ${ }^{1}$
}

\footnotetext{
Moraima Castro Rodrigues ${ }^{2}$; Karen Martins Leão ${ }^{3}$; Elen de Paula Matias Moutinho²; Rossane Pereira da Silva²; Natália do Carmo Silva²; Marco Antônio Pereira da Silva ${ }^{4}$
}

${ }^{1}$ Trabalho apresentado pela primeira autora como parte das exigências para conclusão do curso de bacharelado de Zootecnia do Instituto Federal de Educação, Ciência e Tecnologia Goiano - Campus Rio Verde

${ }^{2}$ Zootecnista pelo Instituto Federal de Educação, Ciência e Tecnologia Goiano Campus Rio Verde;

${ }^{3}$ Médica Veterinária, Profa. Dra. do Instituto Federal de Educação, Ciência e Tecnologia Goiano - Campus Rio Verde;

${ }^{4}$ Zootecnista, Prof. Dr. do Instituto Federal de Educação, Ciência e Tecnologia Goiano - Campus Rio Verde. e-mail: marcotonyrv@yahoo.com.br

\section{Resumo}

O objetivo do trabalho foi avaliar o efeito de diferentes concentrações espermáticas sobre a viabilidade de sêmen suíno refrigerado. Foram realizadas seis colheitas de sêmen, sendo duas por semana, de quatro varrões, com auxílio de manequim, pelo método da mão enluvada. Após a colheita, o ejaculado foi filtrado para retirada da porção gel e diluído com o diluente de refrigeração Proli-Max ${ }^{\circledR}$ acrescido do antibiótico cloridrato de ceftiofur (66,6 
RODRIGUES, M.C. et al. Efeito de diferentes concentrações espermáticas para diluição do semen de varrões sobre a viabilidade do sêmen refrigerado. PUBVET, Londrina, V. 5, N. 19, Ed. 166, Art. 1123, 2011.

$\mathrm{mg} / \mathrm{L}$ ), de acordo com as seguintes concentrações: Tratamento I: $30 \times 10^{6}$ espermatozóides $/ \mathrm{mL}$; tratamento II: $50 \times 10^{6}$ espermatozóides $/ \mathrm{mL}$; e tratamento III: $70 \times 10^{6}$ espermatozóides/mL. Logo após a diluição (T0) e após 24 (T24), 48 (T48) e 72 (T72) horas de refrigeração a $17^{\circ} \mathrm{C}$ avaliou-se motilidade total, motilidade progressiva e vigor. $O$ arranjo estatístico constituiu-se em um esquema fatorial $3 \times 4$ (três concentrações $x$ quatro tempos), com avaliação de análise de variância comparada entre as médias dos grupos seguido do teste de Tukey. O nível de significância considerado foi de $5 \%$ sendo o programa utilizado para as análises estatísticas o software Sisvar versão - 2009. Com concentração final de $50 \times 10^{6}$ espermatozóides $/ \mathrm{mL}$ apresentou melhores resultados de qualidade de sêmen refrigerado de varrões, quando comparado com a concentração de $30 \times 10^{6}$ espermatozóides $/ \mathrm{mL}$.

Palavras-chave: Taxa de diluição, suíno, sêmen refrigerado.

\title{
Effect of different spermatic concentrations for dilution of the semen of boars on the viability of the cooled semen
}

\begin{abstract}
Were carried through six semen harvests, being two per week, of four boars. After the harvest, the ejaculated was filtered and diluted with diluent ProliMax $®$, increased of the antibiotic ceftiofur clorhidrate $(66,6 \mathrm{mg} / \mathrm{L})$, in accordance with the concentrations to follow: Treatment I: $30 \times 10^{6}$ spermatozoid/mL; treatment II: $50 \times 10^{6}$ spermatozoid/mL; and treatment III: $70 \times 10^{6}$ spermatozoid/mL. After the dilution (T0) and after 24 (T24), 48 (T48) and 72 (T72) hours of refrigeration at $17^{\circ} \mathrm{C}$ evaluated total motility, progressive motility and vigor. The final concentration of $50 \times 10^{6}$ spermatozoid/mL presented better resulted of quality of cooled semen of boars.
\end{abstract}

Keywords: dilution tax, swine, cooled semen. 
RODRIGUES, M.C. et al. Efeito de diferentes concentrações espermáticas para diluição do semen de varrões sobre a viabilidade do sêmen refrigerado. PUBVET, Londrina, V. 5, N. 19, Ed. 166, Art. 1123, 2011.

\section{INTRODUÇÃO}

A suinocultura brasileira é bastante desenvolvida e a cada ano surgem novas técnicas de produção e de manejo sanitário, nutricional e reprodutivo, que têm como objetivo a melhoria dos índices zootécnicos do setor, tornando-o ainda mais eficiente. As tecnologias que vem sendo desenvolvidas e aprimoradas na área da reprodução de suínos visam aumentar a taxa de prenhes e o número da leitegada de cada matriz, mas para isso é necessário que o sêmen utilizado seja de boa qualidade, e para que essa qualidade seja comprovada são necessárias várias avaliações relacionadas com a fertilidade, como por exemplo a avaliação da concentração espermática, motilidade total, motilidade progressiva e vigor dos espermatozóides.

A inseminação artificial (IA) é uma biotécnica que auxilia no desenvolvimento do rebanho suíno brasileiro, principalmente em granjas mais tecnificadas e é amplamente difundida na suinocultura moderna.

A IA foi empregada na suinocultura na década de 1930 no Japão e na Rússia, ocorrendo a partir de então, uma evolução lenta e gradativa do uso dessa biotécnica em diferente países, principalmente europeus. No Brasil, somente na década de 1970 foram implantados os primeiros programas comerciais de IA na espécie suína (BORTOLOZZO \& WENTZ, 1997). Em 1975 foram instaladas as duas primeiras centrais de inseminação artificial de suínos (CIA) e a partir dessas centrais ocorreu a difusão dessa técnica para unidades de produção de suínos com central própria e outras centrais criadas no país (BORTOLOZZO et al., 2008).

O aumento da utilização da IA nos países com suinocultura tecnificada, nos últimos anos, mostra que esta biotécnica é viável economicamente, além de potencializar o uso de machos geneticamente superiores, permitir o uso de um menor número de varrões, promove uma maior segurança sanitária e permitir a eliminação de ejaculados de baixa qualidade, evitando desta forma a obtenção de baixas taxas de concepção e tamanho de leitegada reduzido. 
RODRIGUES, M.C. et al. Efeito de diferentes concentrações espermáticas para diluição do semen de varrões sobre a viabilidade do sêmen refrigerado. PUBVET, Londrina, V. 5, N. 19, Ed. 166, Art. 1123, 2011.

Com o emprego da monta natural, preconiza-se um reprodutor para cada grupo de 20 a 25 fêmeas. Com o emprego da IA, o número de fêmeas a serem atendidas por cada macho vai depender do grau de eficiência na utilização de reprodutores, bem como da técnica empregada para a inseminação. Estima-se que, quando o manejo dos doadores de sêmen é otimizado, é possível produzir de 1500 a 2000 doses de sêmen, contendo três bilhões de espermatozóides cada (BORTOLOZZO et al., 2003).

Na monta natural, em razão do elevado número de espermatozóides depositados no trato reprodutivo da fêmea suína, até mesmo ejaculados de baixa qualidade podem alcançar taxas de fecundação aceitáveis. Entretanto, na IA é depositado um menor número de espermatozóides no trato genital da fêmea, em torno de três bilhões por inseminação. O exame de todos os ejaculados colhidos assume um papel importante, para produção de doses de sêmen de boa qualidade e contendo um número adequado de espermatozóides, o que a torna economicamente viável e capaz de proporcionar uma boa taxa de concepção e tamanho de leitegada das porcas inseminadas.

Para a IA de suínos utiliza-se de rotina o sêmen diluído e conservado sob refrigeração a uma temperatura de aproximadamente $17^{\circ} \mathrm{C}$, por até três dias e vários fatores podem influenciar a qualidade espermática durante o processo de conservação, entre eles a susceptibilidade ao choque térmico, velocidade de refrigeração, composição do diluente, os fatores inerentes ao espermatozóide, diferenças entre cachaços e ejaculados e as taxas de diluição do sêmen (BORTOLOZZO et al., 2008).

Com base na necessidade de produção de doses de sêmen de boa qualidade para a IA de suínos, o objetivo do presente trabalho foi avaliar o efeito de diferentes taxas de diluição sobre a viabilidade de sêmen suíno refrigerado. 
RODRIGUES, M.C. et al. Efeito de diferentes concentrações espermáticas para diluição do semen de varrões sobre a viabilidade do sêmen refrigerado. PUBVET, Londrina, V. 5, N. 19, Ed. 166, Art. 1123, 2011.

\section{REVISÃO DE LITERATURA}

\subsection{Características do sêmen de varrões}

O sêmen é caracterizado por ser um líquido, com aspecto cremoso, ligeiramente amarelado e/ou esbranquiçado, sendo que a sua densidade depende da concentração, quando a concentração for menor, vai possuir um aspecto aquoso, o volume varia entre as diversas espécies e dentro de uma mesma espécie, devido à estação do ano, clima, hora, período de repouso sexual do animal e método de colheita (ANJOS, 2006).

O espermatozóide suíno é um dos mais sensíveis ao choque térmico, quando comparado aos de outras espécies. Vários fatores podem estar envolvidos na susceptibilidade dos espermatozóides suínos ao choque térmico, merecendo ênfase a forma da cabeça. Assim, espermatozóides com cabeças grandes e achatadas, como as observadas na espécie suína, seriam mais sensíveis do que os com cabeças menores e mais compactas (WATSON \& PLUMMER, 1985).

O conhecimento profundo da estrutura e do funcionamento da membrana plasmática dos espermatozóides é ponto inicial para o êxito dos processos de manipulação do sêmen, principalmente, tratando-se de espécies como a suína, cujas células apresentam baixa resistência ao choque térmico. A estrutura básica da membrana plasmática de qualquer espécie é o mosaico fluido, constituído por dupla camada lipídica entremeada por moléculas de proteínas. A estrutura da bicamada lipídica é composta por $65 \%$ a $70 \%$ de fosfolipídios, sendo o ácido docosahexanóico (DHA) o principal ácido graxo ligado a estes fosfolipídios, conferindo fluidez à membrana (HOLT, 2000).

\subsection{Métodos para avaliação do sêmen de varrões}

O exame qualitativo do sêmen visa determinar a viabilidade espermática e é empregado para selecionar os ejaculados os quais podem ser refrigerados e utilizados para IA. Entretanto, o exame quantitativo é realizado com o 
RODRIGUES, M.C. et al. Efeito de diferentes concentrações espermáticas para diluição do semen de varrões sobre a viabilidade do sêmen refrigerado. PUBVET, Londrina, V. 5, N. 19, Ed. 166, Art. 1123, 2011.

objetivo de determinar o número de doses inseminantes possíveis de serem produzidas a partir de um ejaculado (BORTOLOZZO et al., 2008).

Os parâmetros mais comumente utilizados para avaliação da qualidade do sêmen, como por exemplo, a motilidade e vigor, devem ser considerados com ressalva ao julgar o potencial fecundante dos espermatozóides, pois estes testes estão pouco correlacionados com à fertilidade obtida in vivo (WOELDERS, 1990). Entretanto, é fundamental que o ejaculado seja submetido a um exame detalhado e apurado antes de ser liberado para IA (BORTOLOZZO et al., 2008).

Após a colheita é descartada a fração gelatinosa que fica retida em um filtro fixado na borda do copo coletor e em seguida o ejaculado deve ser enviado para o laboratório para avaliação macroscópica e microscópica do sêmen (FLOWERS, 1996). O exame macroscópico consiste na avaliação de volume, cor, odor e aspecto do sêmen e durante o exame microscópico avaliase a motilidade total, motilidade progressiva, vigor, aglutinação, morfologia e concentração espermática (AX et al., 2004).

\subsubsection{Percentual de motilidade espermática}

O exame de motilidade deve ser realizado em microscópio óptico, através de uma gota de sêmen entre lâmina e lamínula, com objetivo de avaliar a porcentagem de espermatozóides que estão em movimento. Sendo que para avaliação da motilidade total, é considerado um percentual de todos os espermatozóides que estão se movimentando e para avaliação da motilidade progressiva, é considerado um percentual apenas dos espermatozóides que apresentam movimento retilíneo (WOELDERS, 1990).

O percentual mínimo aceitável de espermatozóides móveis para liberar um ejaculado para processamento é de $70 \%$, sendo que ejaculados com percentuais de células móveis abaixo deste valor devem ser descartados (COLENBRANDER et al., 1993). 
RODRIGUES, M.C. et al. Efeito de diferentes concentrações espermáticas para diluição do semen de varrões sobre a viabilidade do sêmen refrigerado. PUBVET, Londrina, V. 5, N. 19, Ed. 166, Art. 1123, 2011.

\subsubsection{Vigor}

É um parâmetro que avalia a qualidade e intensidade do movimento espermático, levando em consideração o tipo e a direção do movimento. 0 vigor é normalmente estabelecido com base em um uma variação de 0 a 5 e corresponde aos espermatozóides que, estão se movimentando progressivamente sempre levando em consideração a velocidade do movimento (AX et al., 2004).

\subsubsection{Concentração espermática}

Na espécie suína, a determinação da concentração espermática pode ser realizada pela contagem direta em câmara hemocitométrica, pela fotocolorimetria e pela contagem eletrônica de partículas, sendo a estimativa da concentração baseada no aspecto do ejaculado, pouco precisa, não sendo recomendado o uso na rotina das centrais (BORTOLOZZO et al., 2008).

Segundo Corrêa et al. (2001) a concentração é o número de espermatozóides por $\mathrm{mm}^{3}$ de sêmen. Para avaliação da concentração são consideradas tanto as células normais quanto as anormais, e de acordo com essa observação é possível determinar o número de doses a serem produzidas do ejaculado.

As formas de avaliar a concentração espermática são poucas, e entre elas estão: o espermiodensímetro, o espectrofotômetro e a câmara de Neubauer, sendo que essa ultima é a mais utilizada (BEARDEN \& FUQUAY, 1997b). Todas as formas de determinação da concentração espermática do ejaculado de um cachaço devem levar a uma estimativa padronizada da concentração espermática, sendo que em alguns casos pode ocorrer a superestimação, que é considerar um número maior de espermatozóides numa determinada dose de sêmen, do que consta na realidade, ou pode ocorrer também à subestimação, que é o oposto da anterior (KRUEGER et al., 1999).

Segundo Vianna et al. (2004) a superestimação da concentração pode provocar retorno ao cio e consequentemente queda de fertilidade, redução da taxa de parição e no tamanho da leitegada prejudicando o produtor. A análise 
RODRIGUES, M.C. et al. Efeito de diferentes concentrações espermáticas para diluição do semen de varrões sobre a viabilidade do sêmen refrigerado. PUBVET, Londrina, V. 5, N. 19, Ed. 166, Art. 1123, 2011.

correta da concentração espermática fará com que haja a obtenção de doses que consigam uma boa taxa de fertilização dos ovócitos.

De acordo com Corrêa et al. (2001) alguns métodos que avaliam a concentração espermática superestimam a concentração real de espermatozóides, sendo assim na dose inseminante terá uma quantidade menor de espermatozóides que a recomendada, na IA intracervical que é de 3 $\times 10^{9}$ espermatozóides viáveis. Essa falha na avaliação da concentração espermática fará com que chegue um número menor de espermatozóides que o ideal no oviduto reduzindo assim a fertilização (BRUNO et al., 2003).

Vianna et al. (2004) observaram que quando uma concentração espermática esta acima da real, pode mostrar uma falsa situação de que está ocorrendo um excelente manejo dos machos, mostrando um valor acima do real, isso leva a crer que resultará em um maior índice de fertilidade.

O espermiodensímetro é uma das formas de se estimar a concentração espermática e é realizada através do grau de turvação determinando a densidade espermática (BEARDEN \& FUQUAY, 1997b).

De acordo com a densidade óptica observada é feita uma relação com a densidade espermática que será conferida em uma tabela, estimando assim o número de espermatozóides presentes no ejaculado por $\mathrm{mL}$, o espermiodensímetro é o meio mais rápido de estimar a concentração espermática, observando a turbidez ou densidade do ejaculado.

Vianna et al. (2004) afirmam que, existe uma menor precisão do espermiodensímetro quando comparado com outros métodos, principalmente pelo fato de que a densidade do ejaculado pode ser influenciada por sujidades do próprio ejaculado e também vindas do material usado para a colheita do sêmen.

Madeira et al. (2006) citaram que, a determinação da concentração espermática através do aspecto do ejaculado, pode ocorrer uma superestimação do número de espermatozóides e consequentemente das doses inseminantes em relação a câmara de Neubauer, principalmente pelo fato de que o resultado dado pelo espermiodensímetro varia de acordo com o 
RODRIGUES, M.C. et al. Efeito de diferentes concentrações espermáticas para diluição do semen de varrões sobre a viabilidade do sêmen refrigerado. PUBVET, Londrina, V. 5, N. 19, Ed. 166, Art. 1123, 2011.

avaliador, de acordo com estes autores o espectrofotômetro foi o método mais compatível com a técnica padrão, que é a câmara de Neubauer.

A Câmara de Neubauer é um equipamento usado para avaliar a concentração espermática através da contagem das células. É o equipamento de maior precisão para a determinação da concentração espermática (WOELDERS, 1990).

O espectrofotômetro ou fotocolorímetro é um equipamento que avalia a concentração espermática através de passagem de ondas luminosas pela amostra, são aparelhos automáticos e que possuem boa segurança de leitura (WOELDERS, 1990).

\subsection{Refrigeração de sêmen de varrões}

Para prolongar a vida dos espermatozóides é necessária a redução da atividade metabólica do mesmo, através da redução da temperatura de armazenamento e inibidores químicos (JOHNSON et al., 2000).

A manutenção do sêmen suíno sob condições de refrigeração tem se mostrado uma técnica eficiente para a difusão de material genético através dos programas de inseminação artificial, quando o sêmen é adequadamente processado e armazenado, é possível a obtenção de ótimos resultados de prenhez e de tamanho de leitegada utilizando sêmen refrigerado, muitas vezes, o sêmen é de excelente qualidade, mas erros de coleta, processamento, armazenamento ou transporte podem reduzir ou comprometer o potencial fecundante dos espermatozóides, acarretando quedas na fertilidade do rebanho (FERREIRA et al., 2005).

O diluente é uma solução líquida que promove o aumento do volume do ejaculado total, o diluente oferece nutrientes para que os espermatozóides consigam obter energia, e fiquem protegidos contra a alteração do $\mathrm{pH}$ (ALTHOUSE, 1997). O diluente também auxilia nas funcionalidades dos espermatozóides, auxiliando na sua melhor eficiência de fecundação (GADEA, 2003). 
RODRIGUES, M.C. et al. Efeito de diferentes concentrações espermáticas para diluição do semen de varrões sobre a viabilidade do sêmen refrigerado. PUBVET, Londrina, V. 5, N. 19, Ed. 166, Art. 1123, 2011.

Os diluentes de sêmen são compostos com uma ampla variedade de substâncias quimicamente diferentes entre si (açúcares, substâncias tampões, antibióticos), que têm a finalidade de manter os espermatozóides viáveis até o momento de serem introduzidos no trato genital da fêmea (FERREIRA et al., 2005).

Sabe-se que os espermatozóides de suínos são muito sensíveis à baixas temperaturas, principalmente quando utiliza-se uma taxa de refrigeração rápida, o que resulta em uma perda de viabilidade espermática (JOHNSON et al., 2000). Entretanto, Pursel et al. (1972) afirmaram que ao serem mantidos por algumas horas a $15{ }^{\circ} \mathrm{C}$, os espermatozóides adquirem uma resistência gradual ao choque frio. Weber et al. (2003) obteveram bons resultados de viabilidade espermática quando refrigerou o sêmen de varrões por 24 horas a $15{ }^{\circ} \mathrm{C}$, antes de utilizar temperaturas mais baixas.

De acordo com Watson (1996), o choque frio pode estar relacionado com a composição lipídica da bicamada de fosfolipídeos da membrana plasmática, pois estes lipídeos afetam a fluidez da membrana plasmática. Com a redução da temperatura ocorre uma restrição na movimentação lateral dos fosfolipídeos da membrana, resultante da transição de um estado líquido para uma fase gel, sendo esta temperatura de transição diferente para cada tipo de lipídeo da membrana, o que reforça a teoria de que a resistência do espermatozóide choque frio está relacionada à composição dos lipídeos da membrana plasmática (DE LEEUW et al., 1990).

Segundo REIS (1997) a taxa de diluição altera a preservação e a eficiência dos espermatozóides, influenciando assim, na taxa de fertilidade das fêmeas. Matos et al. (2009) mostraram que um ejaculado mais concentrado necessita de mais diluente para chegar a quantidade desejada de espermatozóides por $\mathrm{mL}$ e esse diluente tem a função de proteger o espermatozóide contra o choque térmico.

Watson (1995) observou que altas taxas de diluição provocaram uma redução considerável na viabilidade espermática e acredita que este fato seja 
RODRIGUES, M.C. et al. Efeito de diferentes concentrações espermáticas para diluição do semen de varrões sobre a viabilidade do sêmen refrigerado. PUBVET, Londrina, V. 5, N. 19, Ed. 166, Art. 1123, 2011.

conseqüência de uma redução dos componentes responsáveis pela proteção dos espermatozóides, os quais estão presentes no plasma seminal.

Harrison et al. (1982) citaram que a diluição excessiva das proteínas do plasma seminal, as quais auxiliam na motilidade dos espermatozóides, promovem uma redução na viabilidade espermática, e afirmou também que a adição de albumina pode estimular essa motilidade desejada.

De acordo com Martin Rillo et al. (1994) a taxa de diluição pode influenciar na viabilidade espermática do sêmen refrigerado e sugerem uma taxa de diluição de 1 parte de sêmen para 10 partes de diluente. Entretanto, Ruvalcaba (1994), sugeriu uma diluição de 1 parte de sêmen para 15 de diluente, variando de acordo com a concentração do ejaculado.

A utilização de baixas taxas de diluição na produção de doses inseminantes, ou seja, doses muito concentradas, não são recomendadas pelo fato de que as células espermáticas irão disputar substratos para sua mantença (FLOWERS, 1996). Alexpoulos et al. (1996) também observaram que doses inseminantes com menor quantidade de diluente $e$ consequentemente maior concentração espermática apresentaram uma menor motilidade espermática, quando comparada a doses com maiores taxas de diluição e atribuiu este fato ao ambiente pobre de nutrientes para comportar um grande número de células espermáticas.

Levis (1997) citou que a taxa de diluição deve variar de acordo com as características do diluente, pois, deve ser observado o $\mathrm{pH}$, a pressão osmótica e a capacidade tamponante do mesmo, por esses fatores é que a taxa de diluição tem bastante variação.

A utilização de menores taxas de diluição reduzem o volume da dose inseminante promovendo uma economia de diluente, possibilitando desta forma o uso de diluentes de longa duração, os quais possuem custo mais elevado, porém viabilizam o armazenamento por mais tempo e com melhor qualidade. 
RODRIGUES, M.C. et al. Efeito de diferentes concentrações espermáticas para diluição do semen de varrões sobre a viabilidade do sêmen refrigerado. PUBVET, Londrina, V. 5, N. 19, Ed. 166, Art. 1123, 2011.

\subsection{Inseminação artificial em suínos}

A IA é uma técnica amplamente difundida na suinocultura moderna e é uma biotécnica que potencializa o uso de machos geneticamente superiores, permite o uso de um menor número de varrões, promove uma maior segurança sanitária e permite a eliminação de ejaculados de baixa qualidade, evitando desta forma a obtenção de baixas taxas de concepção e tamanho de leitegada reduzido (BORTOLOZZO et al., 2008).

As pesquisas voltadas para IA estão se direcionando para o desenvolvimento de técnicas mais eficientes para conservação do sêmen, determinação do melhor momento para realização da inseminação e estudos para avaliar o efeito da redução do número de espermatozóides utilizados na inseminação (BORTOLOZZO et al., 2005).

O método empregado tradicionalmente na IA de suínos compreende a utilização de uma pipeta que mimetiza a extremidade do pênis do suíno, sendo esta pipeta fixada na cérvix, permitindo a deposição do sêmen no canal cervical e este procedimento deve ter uma duração de 3 a 5 minutos (BORTOLOZZO et al., 2008).

A dose inseminante indicada para a inseminação artificial tradicional é de aproximadamente três bilhões de espermatozóides, em 80 a $100 \mathrm{~mL}$ de diluente e para se chegar a esse valor é necessária uma eficiente determinação da concentração para que se faça uma correta diluição (BORTOLOZZO et al., 2002).

A inseminação deve ser repetida por duas a três vezes durante o estro, podendo totalizar 12 bilhões de espermatozóides utilizados por porca durante 0 cio (Rath et al., 2000). A necessidade de grande volume e número de espermatozóides na dose inseminante deve-se, provavelmente, às características anatômicas da cérvix e dos cornos uterinos da fêmea suína, tendo os cornos uterinos $50 \mathrm{~cm}$ ou mais, e a cérvix representa grandes barreiras fisiológicas para a chegada das células espermáticas ao reservatório de espermatozóides na junção útero-tubárica (WATSON \& BEHAN, 2002). Durante o transporte espermático no trato reprodutivo feminino, os 
RODRIGUES, M.C. et al. Efeito de diferentes concentrações espermáticas para diluição do semen de varrões sobre a viabilidade do sêmen refrigerado. PUBVET, Londrina, V. 5, N. 19, Ed. 166, Art. 1123, 2011.

espermatozóides estão sujeitos à ação fagocitária dos polimorfonucleares (Rozeboom et al., 1998), que aliada ao refluxo (Steverink et al., 1998), pode ser a principal forma de eliminação espermática do trato genital feminino.

Willmen et al. (1991) trabalhando com inseminação artificial tradicional (IAT) relata que quando a quantidade de células espermáticas foi reduzida de 2,0 para $0,5 \times 10^{9}$, a fertilidade reduziu bastante, passando de $90,2 \%$ para $58,3 \%$.

De acordo com Reed (1985) vários estudos foram desenvolvidos com objetivo de produzir doses inseminantes, com menor número de espermatozóides, porém com células espermáticas viáveis por um maior período de tempo, com capacidade de fecundar uma grande quantidade de oócitos.

Nos últimos anos, foi proposta uma alteração na técnica de IA, preconizando-se a deposição do sêmen no útero (WATSON \& BEHAN, 2002). A técnica consiste no emprego de um cateter com diâmetro aproximado de $3 \mathrm{~mm}$, que é introduzido pelo interior da pipeta tradicional, após a fixação da mesma na cérvix (Bortolozzo et al., 2008). Esta técnica permite a redução do volume da dose inseminante em até dez vezes e do número de espermatozóides da dose de 20 a 60 vezes (MARTINEZ et al., 2001).

Empregando a inseminação artificial intra-uterina (IAU) e a IAT, com um, dois e três bilhões de espermatozóides por dose, Watson \& Behan (2002) demonstraram que a taxa de parto e o número de leitões nascidos totais foram semelhantes, empregando um bilhão de espermatozóides por dose na IAU (86,9\% e 12,1 leitões), em comparação a dois bilhões ( $91,8 \%$ e 12,6 leitões) e três bilhões ( $91,1 \%$ e 12,5 leitões).

Trabalhando com IAU com 1,5 bilhões de espermatozóides e IAT com 3,0 bilhões de espermatozóides, Dallanora et al. (2004) não observaram diferença na taxa de parto e tamanho da leitegada quando comparadas IAU $(92,8 \%$ e 11,6 leitões) e IAT (93,4\% e 11,8 leitões). Foi demonstrado ser possível a obtenção de taxas de prenhez superiores a $85 \%$ e 14 embriões, com a 
RODRIGUES, M.C. et al. Efeito de diferentes concentrações espermáticas para diluição do semen de varrões sobre a viabilidade do sêmen refrigerado. PUBVET, Londrina, V. 5, N. 19, Ed. 166, Art. 1123, 2011.

utilização de 500 milhões de espermatozóides em $20 \mathrm{~mL}$ de diluente (MEZALIRA et al., 2003).

De acordo com Dallanora et al. (2004) a deposição dos espermatozóides no terço inicial do útero pode facilitar a rápida progressão dos mesmos até o reservatório espermático, permitindo desta forma maior retenção de células espermáticas no trato reprodutivo feminino, o que viabiliza a utilização de uma dose inseminante com menor volume e número de espermatozóides. Outra hipótese é que a presença do cateter no corpo ou corno uterino pode induzir a uma maior liberação de hormônios capazes de estimular uma maior contração uterina, o que torna o transporte espermático mais eficiente (Martinez et al., 2002).

Trabalhando com inseminação IAU, Martinez et al.(2002) alcançaram taxas de parto de $76,2 \%$ e $82,9 \%$, utilizando 50 e 150 milhões de espermatozóides em $5 \mathrm{~mL}$ de diluente, em inseminação única. Bennemann et al. (2003) constataram que as taxas de prenhez e o número de embriões de fêmeas submetidas a uma única IAU, foram semelhantes para doses de um e dois bilhões de espermatozóides em $60 \mathrm{~mL}$ de diluente.

\section{MATERIAL E MÉTODOS}

A pesquisa foi realizada na Estação Experimental de Zootecnia do Instituto Federal Goiano Campus - Rio Verde. Foram utilizados quatro varrões selecionados de forma aleatória em uma leitegada recém desmamada. Até alcançarem a puberdade os animais foram mantidos em baia coletiva. Quando atingiram a puberdade aos seis meses de idade, foram alojados em gaiolas individuais. A ração era fornecida duas vezes por dia, sendo dois quilos por trato, a água era fornecida a vontade.

Para a realização do experimento os animais foram adaptados para colheita de sêmen em manequim de metal. O manequim era fixado na sala de coleta e era coberto com uma borracha para evitar que os animais se ferissem 
RODRIGUES, M.C. et al. Efeito de diferentes concentrações espermáticas para diluição do semen de varrões sobre a viabilidade do sêmen refrigerado. PUBVET, Londrina, V. 5, N. 19, Ed. 166, Art. 1123, 2011.

no ato do salto sobre o manequim, podendo assim comprometer o aparelho reprodutor dos mesmos.

No período de adaptação os animais eram conduzidos até o manequim três vezes por semana, durante quinze minutos, após a adaptação, foram realizadas duas colheitas de sêmen por semana.

Para a realização do trabalho foram utilizados seis ejaculados de quatro varrões, sendo as colheitas de sêmen realizadas duas vezes por semana.

Antes de iniciar a colheita de sêmen, os animais eram devidamente higienizados para evitar a contaminação do sêmen coletado. Para colheita de sêmen utilizou-se uma luva de látex, auxiliava-se a exposição do pênis do animal o qual era direcionado para um recipiente de plástico de $500 \mathrm{~mL}$, aquecido em estufa na temperatura de $35-37^{\circ} \mathrm{C}$, coberto por um filtro para retirada da porção gel do ejaculado e em seguida era avaliado o volume do ejaculado, motilidade total (MT\%), motilidade progressiva (MP\%), vigor (V\%) e concentração espermática, antes da diluição.

O meio utilizado para diluição das amostras era constituído por $50 \mathrm{~g}$ de Proli-Max ${ }^{\circledR}$ (Vet Life, Nova Odessa-SP), $66,6 \mathrm{mg} / \mathrm{L}$ de cloridrato de ceftiofur e 1 L de água destilada.

O ejaculado foi divido em três partes para diluição de acordo com os seguintes tratamentos: Tratamento I - Sêmen diluído para uma concentração de $30 \times 10^{6}$ espermatozóides por mL, com Proli-Max ${ }^{\circledR}$; Tratamento II - Sêmen diluído para uma concentração de $50 \times 10^{6}$ espermatozóides por $\mathrm{mL}$, com ProliMax ${ }^{\circledR}$; Tratamento III - Sêmen diluído para uma concentração de $70 \times 10^{6}$ espermatozóides por $\mathrm{mL}$, com Proli-Max ${ }^{\circledR}$.

Após a diluição do sêmen fresco (T0), foram avaliadas a motilidade total, motilidade progressiva e vigor.

As amostras de sêmen diluído foram armazenadas em tubos de centrífuga de $15 \mathrm{~mL}$ com tampa e refrigerados a $17^{\circ} \mathrm{C}$. As avaliações foram novamente realizadas após 24 (T24), 48 (T48), e 72 (T72) horas de refrigeração. 
RODRIGUES, M.C. et al. Efeito de diferentes concentrações espermáticas para diluição do semen de varrões sobre a viabilidade do sêmen refrigerado. PUBVET, Londrina, V. 5, N. 19, Ed. 166, Art. 1123, 2011.

As análises de MT, MP e $\mathrm{V}$ foram realizadas através de microscopia óptica, utilizando uma gota de sêmen colocada entre lâmina e lamínula previamente aquecidas a $37^{\circ} \mathrm{C}$.

Para as análises nos momentos T24, T48 e T72 horas, retiravam-se um $\mathrm{mL}$ de cada amostra com o uso do pipetador automático, que eram colocadas em eppendorfs, previamente identificados com as concentrações espermáticas a serem avaliadas, sendo estas amostras pré-aquecidas por 10 minutos a $37^{\circ} \mathrm{C}$.

O arranjo estatístico constituiu-se em um esquema fatorial $3 \times 4$ (três concentrações $x$ quatro tempos), com avaliação de análise de variância comparada entre as médias dos grupos seguido do teste de Tukey. O nível de significância considerado foi de $5 \%$ sendo o programa utilizado para as análises estatísticas o software Sisvar versão - 2009.

\section{RESULTADOS E DISCUSSÃO}

As Tabelas 1, 2 e 3 apresentam respectivamente as médias de motilidade total, progressiva e vigor sobre os efeitos de diferentes tempos de refrigeração e concentrações espermáticas. Não foi observado interação entre concentração do sêmen diluído e tempo de refrigeração das amostras $(p>0,05)$. Observou-se que todos os parâmetros de qualidade de sêmen avaliados, MT, MP e vigor, foram significativamente maiores com a utilização de uma taxa de diluição a qual proporciona uma concentração final de 50 milhões de espermatozóides por $\mathrm{mL}$ nas doses de sêmen produzidas, quando comparado com a concentração de 30 milhões de espermatozóides por mL.

Os resultados obtidos estão de acordo com Araújo, (2000) e Haugan et al. (2007), que também observaram uma redução da qualidade de sêmen quando diluído em baixa concentração de espermatozóides/mL. 
RODRIGUES, M.C. et al. Efeito de diferentes concentrações espermáticas para diluição do semen de varrões sobre a viabilidade do sêmen refrigerado. PUBVET, Londrina, V. 5, N. 19, Ed. 166, Art. 1123, 2011.

TABELA 1 - Porcentagem de motilidade total e médias de concentrações espermáticas e tempo de refrigeração de sêmen suíno.

\begin{tabular}{llllll}
\hline \multirow{2}{*}{ Concentração } & \multicolumn{5}{c}{ Motilidade Total } \\
\cline { 2 - 6 } & 0 & 24 & 48 & 72 & Média \\
\hline $30 \times 10^{6}$ & 71,25 & 48,75 & 35,00 & 26,75 & $45,44 \mathrm{~b}$ \\
$50 \times 10^{6}$ & 78,12 & 62,70 & 50,20 & 35,20 & $56,56 \mathrm{a}$ \\
$70 \times 10^{6}$ & 75,62 & 57,70 & 40,62 & 31,83 & $51,44 \mathrm{ab}$ \\
Média & $75,00 \mathrm{a}$ & $56,39 \mathrm{~b}$ & $41,94 \mathrm{c}$ & $31,26 \mathrm{~d}$ \\
\hline
\end{tabular}

Fontes de variação

Concentração

0,0009

Tempo

0,0000

Concentração x Tempo

0,9388

CV (\%)

39,86

*Letras minúsculas diferentes na coluna diferem entre si a $5 \%$ de probabilidade comparando a MT entre os grupos. *Letras minúsculas diferentes na linha diferem entre si a $5 \%$ de probabilidade comparando a MT entre os tempos de refrigeração. CV - Coeficiente de variação.

Tabela 2 - Porcentagem de motilidade progressiva e médias de concentrações espermáticas e tempo de refrigeração de sêmen suíno.

\begin{tabular}{llllll}
\hline & \multicolumn{5}{c}{ Motilidade Progressiva } \\
\cline { 2 - 6 } Concentração & 0 & 24 & 48 & 72 & Média \\
\hline $30 \times 10^{6}$ & 63,54 & 35,83 & 27,41 & 20,70 & $36,87 \mathrm{~b}$ \\
$50 \times 10^{6}$ & 68,75 & 53,33 & 40,00 & 27,04 & $47,28 \mathrm{a}$ \\
$70 \times 10^{6}$ & 66,66 & 45,62 & 32,91 & 27,91 & $43,28 \mathrm{ab}$ \\
Média & $66,31 \mathrm{a}$ & $44,93 \mathrm{~b}$ & $33,44 \mathrm{c}$ & $25,22 \mathrm{c}$ & \\
\hline
\end{tabular}

\section{Fontes de variação}

\begin{tabular}{ll}
\hline Concentração & 0,0015 \\
Tempo & 0,0000 \\
Concentração x Tempo & 0,7432 \\
CV $(\%)$ & 46,80
\end{tabular}

\footnotetext{
* Letras minúsculas diferentes na coluna diferem entre si a $5 \%$ de probabilidade comparando a MP entre os grupos. *Letras minúsculas diferentes na linha diferem entre si a $5 \%$ de probabilidade comparando a MP entre os tempos de refrigeração. CV - Coeficiente de variação.
} 
RODRIGUES, M.C. et al. Efeito de diferentes concentrações espermáticas para diluição do semen de varrões sobre a viabilidade do sêmen refrigerado. PUBVET, Londrina, V. 5, N. 19, Ed. 166, Art. 1123, 2011.

Tabela 3 - Porcentagem de vigor e médias de concentrações espermáticas e tempo de refrigeração de sêmen suíno.

\begin{tabular}{llllll}
\hline \multirow{2}{*}{ Concentração } & \multicolumn{5}{c}{ Motilidade Vigor } \\
\cline { 2 - 6 } & 0 & 24 & 48 & 72 & Média \\
\hline $30 \times 10^{6}$ & 2,58 & 1,75 & 1,20 & 1,08 & $1,65 \mathrm{~b}$ \\
$50 \times 10^{6}$ & 2,87 & 2,20 & 1,83 & 1,25 & $2,04 \mathrm{a}$ \\
$70 \times 10^{6}$ & 2,58 & 2,04 & 1,54 & 1,12 & $1,82 \mathrm{ab}$ \\
Média & $2,68^{\mathrm{a}}$ & $2,00 \mathrm{~b}$ & $1,52 \mathrm{c}$ & $1,15 \mathrm{~d}$ & \\
\hline
\end{tabular}

\section{Fontes de variação}

Concentração

Tempo

Concentração x Tempo

CV $(\%)$
0,0008

0,0000

0,7158

38,13

*Letras minúsculas diferentes na coluna diferem entre si a $5 \%$ de probabilidade comparando 0 vigor entre os grupos. *Letras minúsculas diferentes na linha diferem entre si a $5 \%$ de probabilidade comparando o vigor entre os tempos de refrigeração. CV - Coeficiente de variação.

Neste trabalho foi observado que as taxas de diluição, na concentração espermática final de $50 \times 10^{6}$ espermatozóides $/ \mathrm{mL}$, mostrou-se mais eficiente para manutenção da viabilidade espermática.

Entretanto, para produção de uma dose inseminante contendo $3 \times 10^{9}$

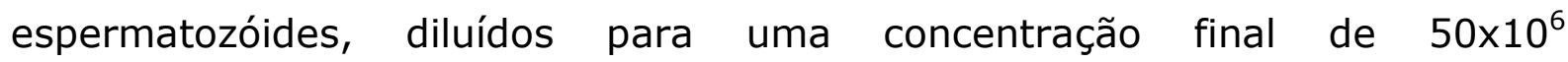
espermatozóides $/ \mathrm{mL}$, o volume final desta dose será de apenas $60 \mathrm{~mL}$ e tradicionalmente as doses inseminantes possuem 80 a $100 \mathrm{~mL}$.

No presente trabalho foi observado que na concentração espermática de $30 \times 10^{9}$ espermatozóides $/ \mathrm{mL}$, ou seja, uma taxa de diluição alta, a viabilidade espermática caiu de forma considerável, fato também encontrado por Watson (1995) que relatou que seja devido a redução dos componentes do plasma seminal que auxiliam na motilidade dos espermatozóides. Harrison et al. 
RODRIGUES, M.C. et al. Efeito de diferentes concentrações espermáticas para diluição do semen de varrões sobre a viabilidade do sêmen refrigerado. PUBVET, Londrina, V. 5, N. 19, Ed. 166, Art. 1123, 2011.

(1982) também observaram esse fato, e concluiu que a adição de albumina pode melhorar essa situação.

$\mathrm{Na}$ concentração espermática contendo $70 \times 10^{6}$ espermatozóides $/ \mathrm{mL}$, pode ser visto que a alta concentração espermática não foi tão vantajosa numericamente em relação a concentração contendo $50 \times 10^{6}$ espermatozóides $/ \mathrm{mL}$, isso pode ter ocorrido devido a elevada quantidade de espermatozóides que disputam pela pequena quantidade de substratos presentes no diluente. Flowers (1996) e Alexpoulos (1996), também observaram que doses muito concentradas apresentaram menor motilidade espermática quando comparadas com doses inseminantes mais diluídas. A economia no diluente em doses inseminantes mais concentradas pode ser vantajosa considerando a redução de custos, porém pode ter a desvantagem da redução da viabilidade espermática.

Com o uso da concentração espermática de $50 \times 10^{6}$ espermatozoides $/ \mathrm{mL}$, ocorrerá uma redução do volume da dose inseminante, na IA tradicional, esse fator pode ser prejudicial. Porém, para a IAU, isso pode não ser um problema, pois a dose inseminante será depositada em um local onde uma maior quantidade de células espermáticas chegarão no terço final do útero, conforme foi observado por Dallanora et al. (2004).

Com a utilização da IAU, pode ser obtido grande economia de diluente e de células espermáticas, como nas doses inseminantes contendo 1,5 bilhões de espermatozóides, paralelo a isso, tem-se o mesmo índice de fertilidade quando comparado a uma dose inseminante de 3 bilhões de espermatozóides por dose inseminante usada na IAT. (Dallanora et al., 2004).

Pequenos volumes de doses inseminantes podem ser eficientes na IAU, conforme demonstrado por Martinez et al. (2002) que conseguiram uma taxa de parição de $82,9 \%$ com apenas $150 \times 10^{6}$ espermatozóides.

Em casos menos extremos, se utilizado uma dose inseminante de 1 bilhão de espermatozóides, e a concentração de 50 milhões que foi a melhor encontrada neste trabalho, teremos uma dose inseminante de $20 \mathrm{~mL}$, que pode ser usada através da IAU. 
RODRIGUES, M.C. et al. Efeito de diferentes concentrações espermáticas para diluição do semen de varrões sobre a viabilidade do sêmen refrigerado. PUBVET, Londrina, V. 5, N. 19, Ed. 166, Art. 1123, 2011.

Talvez, a realização de IAU com doses inseminantes produzidas de $50 \times 10^{6}$ espermatozóides $/ \mathrm{mL}$ possa levar a obtenção de bons índices reprodutivos. Porém, para a realização da IAU são necessários maiores cuidados no momento da IA e uma maior qualificação dos técnicos responsáveis pela inseminação.

A maior concentração espermática por $\mathrm{mL}$ da dose inseminante, fará com que o produtor economize no gasto com diluentes, porém, pode ocorrer falha na fertilização das matrizes pelo fato do reduzido volume inseminante não viabilizar a chegada dos espermatozóides ao local desejado, pois, segundo Watson \& Behan (2002), os cornos uterinos da matriz são bastante extensos e sua cérvix possui características anatômicas que dificultam a chegada dos espermatozóides na junção útero-tubárica, por isso há a necessidade de grande volume e número de espermatozóides na dose inseminante, porém estes mesmos autores concluíram que é possível reduzir o número de células espermáticas, assim como o volume da dose inseminante (DI), sem prejuízo à fertilidade, quando a deposição do sêmen é realizada após a cérvix.

Segundo Corrêa et al. (2001) no método de inseminação artificial intracervical a dose inseminante mais utilizada é a de 2,5 a $3,0 \times 10^{9}$ de espermatozóides. Watson \& Behan. (2002) relataram que o uso de IA intracervical e IA pós-cervical permitiu o uso de doses inseminantes com menor número de espermatozóides, e que em aproximadamente meia década de

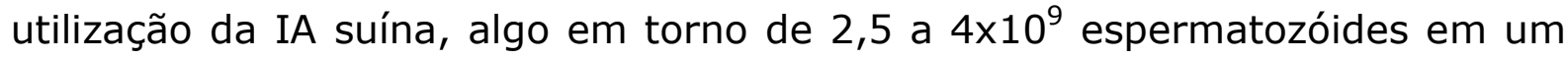
volume entre 80 a $100 \mathrm{~mL}$ de diluente têm sido o suficiente para alcançar a fertilidade desejada na IA convencional e na IA intracervical.

Bortolozzo et al. (2002), relataram que com a redução do número de espermatozóides por dose inseminante para $1 \times 10^{9}$, possibilita a produção de mais doses por ejaculado, e a redução de machos no plantel, porém esse descarte de machos não pode ser muito grande, pois, se houver a necessidade de descartar algum ejaculado ou algum animal morrer ou adoecer, é necessário outro varrão para a reposição deste. 
RODRIGUES, M.C. et al. Efeito de diferentes concentrações espermáticas para diluição do semen de varrões sobre a viabilidade do sêmen refrigerado. PUBVET, Londrina, V. 5, N. 19, Ed. 166, Art. 1123, 2011.

Neste trabalho foi observada uma redução na qualidade do sêmen refrigerado de varrões com o passar do tempo de refrigeração, este fato foi observado em todos os parâmetros avaliados, a redução do número de espermatozóides por dose inseminante aumenta a necessidade de mais análises laboratoriais, porém reduziu o número de colheitas com mais trabalho nos laboratórios em avaliações de melhor precisão e confiabilidade (BORTOLOZZO et al., 2005).

Matos et al. (2009) mostraram que independente da dose inseminante não houve diferenças na taxa de parição e no tamanho da leitegada, utilizando $3,5 \times 10^{9} / 100 \mathrm{~mL}$ de espermatozóides e $2 \times 10^{9} / 100 \mathrm{~mL}$, com dois tipos de pipetas. A redução do número de espermatozóides para $2 \times 10^{9} / 100 \mathrm{~mL}$ na dose inseminante foi viável, pois, houve uma adequada fecundação sem afetar o desempenho das matrizes e sem diminuir a sobrevivência espermática.

A redução do volume da dose inseminante pode ser prejudicial para a obtenção de boas taxas de parição e tamanho da leitegada devido às características anatômicas do trato reprodutor da fêmea suína. Entretanto, com a utilização da IAU vários pesquisadores obtiveram boas taxas de parição e tamanho de leitegada utilizando doses inseminantes com menor numero de espermatozóides e menor volume de dose inseminante (WATSON \& BEHAN, 2002)

Com a redução do volume da dose inseminante resultando numa economia de diluente, viabilizando desta forma a aquisição de diluentes de longa duração que são de custo mais elevado e que proporcionam o aumento do período de estocagem do sêmen sem que este perca a qualidade.

Com a redução do número de espermatozóides por dose inseminante, é possível obter melhores condições de manejo do reprodutor e maior quantidade de fêmeas inseminadas por um só varrão, reduzindo assim o custo de produção. 
RODRIGUES, M.C. et al. Efeito de diferentes concentrações espermáticas para diluição do semen de varrões sobre a viabilidade do sêmen refrigerado. PUBVET, Londrina, V. 5, N. 19, Ed. 166, Art. 1123, 2011.

\section{CONCLUSÃo}

Foi possível verificar no presente estudo que a taxa de diluição na concentração final da dose inseminante de $50 \times 10^{6}$ espermatozóides/mL apresentou melhores resultados de qualidade de sêmen refrigerado de varrões, quando comparado com a concentração de $30 \times 10^{6}$ espermatozóides $/ \mathrm{mL}$.

\section{REFERÊNCIAS BIBLIOGRÁFICAS}

ALEXPOULOS, C.; BOSCOS, C.; SARATSIS, P.H. The effect of storage time and number of spermatozoa per insemination dose on semen characteristics and fertility capacity of boar semen diluted in Beltsville Thaw Solution (BTS) extender. Anim. Sci., v.62, p.599-604, 1996.

ALTHOUSE, G.C. Comparison of currently used semen extenders in the swine industry. Compend Contin Educ Pract Vet, v.19, n.6, p. 777-782, 1997.

ANJOS, J. E. A. B. Trabalho de conclusão de curso na área de reprodução animal. 54p. Faculdade Integrada - UPIS Distrito Federal. 2006.

ARAUJO, A.A. Mise au point d'un dilueur de conservation en milieu liquide pour la semence ovine en vue de I'insémination artificielle. 81f. Tese (Doutorado em Ciências da Vida) Université François de Tours, Tours, France. 2000.

AX, R. L.; DALLY, M. R.; DIDION, B.A.; LENZ, R. W.; LOVE, C.C.; VARNER, D. D.; HAFEZ, B.; BELLIN, M. E.; Avaliação do Sêmen. In: HAFEZ, E.S.E.; HAFEZ, B. Reprodução Animal. 70 ED. Barueri: Manole, 2004. Cap.25, p. 369-379.

BEARDEN, H.J.; FUQUAY, J.W. Semen evaluation. In: BEARDEN, H.J.; FUQUAY, J.W. Applied Animal Reproduction. $4^{\text {th }}$ Ed.New Jersey: Prentice Hall, Cap. 15, p.159-170,1997b.

BENNEMANN, P.E.; MILBRADT, E.; DIEHL, G.N.; VIDOR, R.; FRIES, H.C.C.; BERNARDI, M.; WENTZ, I.; BORTOLOZZO, F.P. Desempenho reprodutivo de fêmeas suínas submetidas à inseminação intra-uterina com 1 e 2 x 109 espermatozóides em diferentes intervalos préovulatórios. In: Congresso Brasileiro de Veterinários Especialistas Em Suínos, 11. Goiânia. Anais. Concórdia: Embrapa Suínos e Aves, 2003. p.211-212. 2003.

BORTOLOZZO F, P, WENTZ. I. \& DALLANORA. D., Situação atual da inseminação artificial em suínos. Acta Scientiae Veterinariae. 33(1): 17- 32, Review Article Pub. 604. 2005.

BORTOLOZZO F.P., WENTZ I. \& DALLANORA. D.. Avanços na inseminação artificial de suínos. In: Anais dos Encontros Técnicos ABRAVES-RS (Estrela, Brasil). pp.1-20. 2002.

BORTOLOZZO F, P, WENTZ. I. Situação atual da inseminação artificial em suínos no Brasil. Rev. Bras. Reprod. Animal., v. 21, p.13-15,1997.

BORTOLOZZO F.P., DALLANORA. D., BERNARDI, M. L., BENNEMANN, P. E., WENTZ, I. Técnicas associadas à inseminação artificial no suíno que visam a redução do número de 
espermatozóides necessários por fêmea por ano. Rev. Bras. Reprod. Anim., p.133-139, 2003.

BORTOLOZZO F.P., BERNARDI, M. L., BENNEMANN, P. E., WENTZ, I. Inseminação Artificial em Suínos. In: GONÇALVES, P. B. D., FIGUEIREDO, J. R., FREITAS, V. J. F. Biotécnicas Aplicadas à Reprodução Animal. São Paulo: Roca, $2^{\circ}$ Ed. Cap. 7, p. 125-144. 2008.

BRUNO, D.G.; NAMINDOME, A.; VIANNA, W.L. ROSSETO, A.C. RODRIGUES, P.H.M. MORETTI, A.S. Estudos comparativos da eficiência de diferentes técnicas de mensuração da concentração espermática em suínos. Anais do XI Congresso da Abraves, v. 2, p.223-224, 2003.

COLENBRANDER, B., FEITSMA, H., GROOTEN, H. J. Optimizing sêmen production for artificial insemination in swine. J. Reprod. Fert., p. 207-215, suppl. 48, 1993.

CORRÊA, M.N.; MEINCKE, W.; LUCIA, T. Inseminação Artificial em Suínos. Pelotas - RS, 181p. 2001.

DALLANORA , D. MEZALIRA, A ., BERNARDI, M. L., BORTOLOZZO, F. P. Desempenho reprodutivo de fêmeas suínas inseminadas pela técnica intra-uterina ou tradicional. Pesq. Agropec. Bras., v. 39, 2004.

DE LeEUW, F. E., CHEN, H. C., COLENBRANDER, B., VERKLEIJ, A. J. Cold-induced ultrastructural changes in bull and boar sperm plasma membranas. Cryobiology, v. 27, p. 171-183, 1990.

FERREIRA, F. M.; WENTZ, I.; SCHEID, I. R. et al. Comportamento de monta e características seminais de suínos jovens landrace e large white. Ciência Rural, v. 35, p.131-137, 2005.

FLOWERS, W.L. Semen evaluation, extension, packaging and transportation methods. American Association of Swine Practtioners, 27., Nashville, Tenessee. Proceedings. p.469-479, 1996.

GADEA, J. Semen extenders used in the artificial insemination of swine. A review. Spanish J. Agr. Res., v.1, n.2, p.17-27, 2003.

HARRISON, R.A.P., DOTT, H.M., FOSTER, G.C.,. Bovine serum albumin, sperm motility, and the dilution effect. J. Exp. Zool. 222, 81-88. 1982.

HAUGAN; T, GROHN,Y.T; KOMMISRUD, E; ROPSTAD, E.; REKSEN, O. Effects of sperm concentration at semen collection and storage period of frozen semen on dairy cow conception. Animal Reproduction v.97, n.1-2, p.1-11, 2007.

HOLT, W.V. Fundamental aspects of sperm cryobiology: the importance of species and individual differences. Theriogenology, v.53, n.1, p.47-58, 2000.

JOHNSON, L.A., WEITZE, K.F., FISER, P., MAXWELL, W. M. C., Storage of boar semen., Animal Reproduction Science., 62, Sydney, pp. 143-172, 2000.

KRUEGER, C., RATH, D., JOHNSON, L.A. Low dose insemination in synchronized gilts. Theriogenology, v.52, p.1363-1373, 1999.

LEVIS, D.G. Hazard analysis of critical control points in an on-farm artificial insemination laboratory. In: George A. Young Swine Conference And Annual Nebraska Spf Swine Conference. 38, , Lincoln. Proc..., Lincoln: 1997, p.58-74. 1997. 
MADEIRA, E. M; BIANCHI, I; CALDERAM, K; MASCHIO, É. F; CORRÊA, É. K; PERONDI, A; LUCIA JR., THOMAZ; COLARES, T; CORRÊA, M. N. Comparação de diferentes métodos para avaliação da concentração de sêmen suíno. Universidade Federal de Pelotas, Pelotas/RS/Brasil. XV CONGRESSO DE INICIAÇÃO CIENTÍFICA. 2006

MARTIN RILLO, S.; GRANADOS, L.; RUVALCABA, J.A.G.; I.A Porcina: Situacion actual y tecnologia. In: CONGRESSO NACIONAL DR REPRODUCTION PORCINA. 3, 1994. Rosário, Argentina, Anais, Rosário, Argentina: 1994, p.65-78.

MARTINEZ, E.A.; VAZQUEZ, J.M.; ROCA, J.; LUCAS, X.; GIL, M.A.; PARRILLA, I.; VAZQUEZ, J.L.; DAY, N. Minimum number of spermatozoa required for normal fertility after deep intrauterine insemination in non-sedated sows. Reproduction, v.123, p.163$170,2002$.

MARTINEZ, E.A.; VAZQUEZ, J.M.; ROCA, J.; LUCAS, X.; GIL, M.A.; PARRILLA, I.; VAZQUEZ, J.L.; DAY, N. Successful non-surgical deep intrauterine insemination with small numbers of spermatozoa in sows. Reproduction, v.122, p. 289-296, 2001.

MATOS, D. L; ARAUJO, A. A. de; ROBERTO, IARA GONÇALVES; TONIOLLI, RICARDO. Sobrevivência espermática em diferentes taxas de diluição do sêmen do varrão Rev. Bras. Saúde Prod. An., v.10, n.4, p.999-1009 out/dez, 2009.

MEZALIRA, A., DALLANORA, D., SCHIMIDT, A. C. T., ZILLI, R., BERNARDI, M. L., WENTZ, I., BORTOLOZZO, F. P. Inseminação intra-uterina em fêmeas suínas com redução no volume e numero de espermatozóides. In: XI CONGRESSO DA ASSOCIAÇÃO BRASILEIRA DE VETERINARIOS ESPECIALISTAS EM SUINOS, 2003. Goiânia. Anais do XI Congresso da Associação Brasileira de Veterinários Especialistas em Suínos, p. 217-218, 2003.

PURSEL, V.G.; JOHNSON, L. A.; SCHULMAN, L.L. Interation of extender composition and incubation period on cold shock susceptibility of boar spermatozoa. J. Anin. Sci., v.35, n.3, p.580-584, 1972.

RATH, D.; KRUEGER, C.; JOHNSON, L.A. Low dose insemination technique in the pig. In: INTERNATIONAL CONFERENCE ON BOAR SEMEN PRESERVATION, 4., 2000, Beltsville. Proceedings. Lawrence: Allen Press,. p.115-118, 2000.

REED, H.C.B., Current use of frozen boar semen: future need of frozen boar semen. In: Johnson, L.A., Larsson, K.Eds.., Deep Freezing Boar Semen. Proc. 1st Int. Conf. Deep Freezing of Boar Semen. Swedish Univ. Agric. Sciences, Uppsala, pp. 225-237. 1985.

REIS, F. T. Colheita, avaliação e manipulação do ejaculado de suínos. Revista Brasileira Reprodução Animal, v. 21, n. 3, p. 22-29, 1997.

ROZEBOOM, K.J.; TROEDSSON, M.H.T.; CRABO, B.G. Characterization of uterine leukocyte infiltration in gilts after artificial insemination. Journal of Reproduction and Fertility, v.114, p.195- 199, 1998.

RUVALCABA, J.A.G. Improvement in reproductive performance in pigs with artificial insemination and MR-A long term preservation diluent. In: Annual Meeting Of American Association Of Swine Practioners, 25, , Nebrasca, Proc... Nebrasca: 1994, p.1-5. 1994.

STEVERINK, D.W.B.; SOEDE, N.M.; BOUWMAN, E.G. Semen backflow after insemination and its effect on fertilization results in sows. Animal Reproduction Science, v.54, p.109-119, 1998. 
VIANNA, W. L; BRUNO, D.G; NAMINDOME, A; ROSSETO, A.C; RODRIGUES, P.H.M. MO RETTI, A de S. Estudo Comparativo da Eficiência de Diferentes Técnicas de Mensuração da Concentração Espermática em Suínos. R. Bras. Zootec. v.33, n.6, p.2054-2059, 2004.

WATSON, P.F.; BEHAN, J.R. Intrauterine insemination of sows with reduced sperm numbers: results of a commercially based field trial. Theriogenology, v.57, p.1683-1693, 2002.

WATSON, P.F., Recent developments and concepts in the cryopreservation of spermatozoa and the assessment of their post-thawing function. Reprod. Fertil. Dev. 7, 871-891. 1995.

WATSON, P. F. Cooling of spermatozoa and fertilizing capacity. Reprod. Anim., v. 31, p. 135$140,1996$.

WATSON, P. F., PLUMMER, J. M. The responses of boar sperm membranes to cold shock and cooling. In: I CONFERENCE ON DEEP FREEZING OF BOAR SEMEN, Uppsala. Proceedings of I Conference On Deep Freezing Of Boar Semen, 1985, p. 113-127. 1985.

WEBER, D., BENNEMANN, P. E., WENTZ, I., BORTOLOZZO, F. P. Avaliação do custo de doses inseminantes em sistema fechado. In: XI CONGRESSO DA ASSOCIAÇÃO BRASILEIRA DE VETERINÁRIOS ESPECIALISTAS EM SUÍNOS, 2003. Goiânia. Anais do XI Congresso da Associação Brasileira de Veterinários Especialistas Em Suínos, , p. 245-246, 2003.

WILLMEM, T., RABELER, J., EVERWAND, A., WABERSKI, D., WEITZE, K.F.,. Influence of seminal plasma and oestrogens in the inseminate of fertilization rate, sperm transport and ovulation time. In: Rath, D., Johnson, L.A., Weitze, K.F._Eds.., Boar Semen Preservation III. Proc. 3rd Int. Conf. Boar Semen Preservation. Reprod. Domest. Anim. Suppl. 31 Blackwell, Berlin, pp. 379-383. 1991.

WOELDERS, H. Overview of in vitro methods for evaluation of semen quality. Reproduction in Domestic Animals. Supplement. v. 1, p. 145-164. 1990. 